\title{
Duration of active psychosis and functional outcomes in first-episode non-affective psychosis
}

\author{
José María Pelayo-Terán ${ }^{\mathrm{a}, \mathrm{b}, \mathrm{c}, *}$, Virginia Gajardo-Galánn ${ }^{\mathrm{a}, \mathrm{b}, \mathrm{d}}$, Marcos Gómez-Revuelta ${ }^{\mathrm{a}, \mathrm{b}}$, \\ Victor Ortiz-García de la Foz ${ }^{\mathrm{a}, \mathrm{b}}$, Rosa Ayesa-Arriola ${ }^{\mathrm{a}, \mathrm{b}}$, Rafael Tabarés-Seisdedos ${ }^{\mathrm{b}, \mathrm{e}}$, \\ Benedicto Crespo-Facorro ${ }^{\mathrm{a}, \mathrm{b}}$ \\ a University Hospital Marqués de Valdecilla, IFIMAV, Department of Psychiatry, School of Medicine, University of Cantabria, Santander, Spain \\ ${ }^{\mathrm{b}}$ CIBERSAM, Centro Investigación Biomédica en Red Salud Mental, Madrid, Spain \\ ${ }^{\mathrm{c}}$ Unidad de Gestión Clínica de Psiquiatría y Salud Mental, Hospital El Bierzo, Servicio de Salud de Castilla y León (SACYL), Ponferrada, León, Spain \\ ${ }^{\mathrm{d}}$ Hospital de Merida, Servicio Estremeño de Salud (SES), Mérida, Badajoz,Spain \\ ${ }^{\mathrm{e}}$ Department of Psychiatry, University of Valencia, CIBERSAM, Valencia, Spain
}

\section{A R T I C L E I N F O}

\section{Article history:}

Received 3 December 2017

Received in revised form 6 March 2018

Accepted 8 March 2018

Available online 31 March 2018

\section{Keywords:}

Schizophrenia

Early intervention

Positive symptoms

Prognosis

Prospective study

Neurotoxicity hypothesis

\begin{abstract}
A B S T R A C T
Background: The duration of untreated psychosis (DUP) has been associated with negative outcomes in psychosis; however, few studies have focused on the duration of active psychotic symptoms after commencing treatment (DAT). In this study, we aimed to evaluate the effect of DUP and DAT on functional long-term outcomes ( 3 years) in patients with early psychosis.

Methods: We evaluated the Scale for the Assessment of Positive Symptoms (SAPS) at frequent intervals for 3 years after presentation to determine the DAT for 307 individuals with first-episode psychosis together with DUP and clinical variables. The functional outcomes were assessed using the Disability Assessment Scale (DAS) at three years, and functional recovery was defined as minimal impairment and return to activity. Associated variables, DAT and DUP were included in logistic regression models to predict functional outcomes. Receiver operating characteristic curves and Youden's index were applied to assess the best cut-off values.

Results: DAT, (Wald: 13.974; ExpB: 1.097; $\mathrm{p}<0.001$ ), premorbid adjustment, initial BPRS score, gender, age of onset and schizophrenia diagnosis were significant predictors of social functioning, whereas only premorbid adjustment (Wald: 11.383; ExpB:1.009), DAT (Wald: 4.850; ExpB: 1.058; $\mathrm{p}=0.028$ ) and education were significant predictors of recovery. The optimal cut-off of DAT for predicting social functioning was 3.17 months for DAT (sensitivity: 0.68; specificity: 0.64; Youden's index: 0.314).

Conclusions: DAT is strongly related to functional outcomes independent of the DUP period or other variables. As a modifiable variable, the reduction of the DAT should be considered a main focus of intervention from the onset of the illness to improve long-term outcomes.
\end{abstract}

(c) 2018 Elsevier Masson SAS. All rights reserved.

\section{Introduction}

Deterioration has historically been considered a cardinal feature of schizophrenia [1]. Nonetheless, a significant number of patients have the potential to achieve clinical remission and functional recovery after the onset of the illness [2,3]. Historical research on early detection and intervention in schizophrenia

\footnotetext{
* Corresponding author at: University Hospital Marqués de Valdecilla-IFIMAV CIBERSAM, Department of Psychiatry, School of Medicine, University of Cantabria, Santander, Avda. Valdecilla, s/n. | 39008 SANTANDER, Cantabria, Spain.

E-mail addresses: pelayoteran@gmail.com, josemariapelayot@saludcastillayleon.es (J.M. Pelayo-Terán).
}

suggested that lengthy active psychotic symptoms might prompt a worse outcome [4]. Active positive symptoms represent a dangerous mental state that might be "biologically toxic," leading to the notion of the deleterious effect on the brain in patients with acute active psychosis [5]. Based on the weight of accumulating evidence against a uniformly deteriorating or degenerative course across time, the concept of a "critical period" proposes that most of the clinical and psychosocial deterioration occurs within the first 2 to 5 years after psychosis onset [6,7]. This period is notable for a high risk of antipsychotic treatment dropout, relapse and suicide [8,9].

A lengthy DUP may negatively influence illness prognosis with regard to symptomatic response, remission and functional outcomes [10-12]. Some cognitive [13,14] and imaging studies [15,16], 
but not all [17,18], have provided evidence to support this hypothesis, and it has been suggested that there is minimal evidence of an association between untreated psychosis and brain structure in psychosis [19,20].

Surprisingly, little attention has been paid to the likely harmful effects of the duration of active psychotic symptoms after treatment is initiated (DAT) on clinical and functional outcomes in schizophrenia. This relationship can be suspected by the association clinical and functional outcomes with time to remission or relapses in patients with a first episode of psychosis. Time to remission and non-early remission has been previously associated to both clinical and functional outcomes at long term [21-23]. Number of relapses have been previously associated to a poorer outcome in patients with schizophrenia or a first episode of psychosis $[24,25]$. With regard to the period of active psychosis, in a previous study, patients with first episode of psychosis and a longer DAT showed a negative intellectual course [26]. Additionally, it has been reported that the entire duration of active psychosis (DAP: DUP plus the DAT) is a better predictor of severe negative symptoms at 24 months than DUP in patients with a first episode of psychosis [27].

We aimed to investigate the effect of the DAP before or after the start of treatment (DUP or DAT, respectively) on clinical and functional outcomes in the long term (3 years) in early psychosis. We hypothesized that both variables, DUP and DAT may have an additive negative effect on the long term functional outcomes.

\section{Experimental procedures}

\subsection{Study setting}

This cohort was obtained from an ongoing epidemiological and three-year longitudinal intervention program of first-episode psychosis (PAFIP) conducted at the outpatient clinic and the inpatient unit at the University Hospital Marques de Valdecilla (Cantabria, Spain) [28]. Conforming to the international standards for research ethics, this program was approved by the local Institutional Review Board and conforms to the provisions of the Declaration of Helsinki. Patients meeting the inclusion criteria provided their written informed consent to be included in the PAFIP.

\subsection{Subjects}

All referrals to PAFIP between February 2001 and May 2011 were screened for eligibility with respect to the following criteria: 1) age $15-60$ years; 2 ) living in the catchment area; 3 ) experiencing their first episode of psychosis; 4) no prior treatment with antipsychotic medication or, if previously treated, a total lifetime of adequate antipsychotic treatment of less than 6 weeks; and 5) DSM-IV criteria for brief psychotic disorder, schizophreniform disorder, schizophrenia, or schizoaffective disorder. Patients were excluded for any of the following reasons: 1) DSM-IV criteria for drug dependence or mental retardation and 2) a history of neurological disease or head injury. The diagnoses were confirmed using the Structured Clinical Interview for DSM-IV (SCID-I) [29] conducted by an experienced psychiatrist 6 months after the baseline visit. Our operational definition for a "first episode of psychosis" included individuals with non-affective psychosis who had not previously received antipsychotic treatment, regardless of the duration of untreated psychosis.

\subsection{Study design}

This prospective clinical study evaluated the effects of DUP, DAT and DAP in the clinical and functional outcomes in individuals with first-episode non-affective psychosis (DSM-IV criteria). All patients with DUP and DAT measurements followed up in PAFIP and with clinical and functional assessments at the end point ( 3 years) were included in the final analysis.

\subsection{Medication}

This is an analysis of three different, randomized, flexible-dose and open-label clinical trials, PAFIP I, II and III [30,31]. In each trial, the patients were randomly assigned to receive olanzapine (5$20 \mathrm{mg} /$ day), risperidone (2-6 mg/day), haloperidol (3-9 mg/day), aripiprazole $(5-30 \mathrm{mg} /$ day), ziprasidone $(40-160 \mathrm{mg} /$ day $)$ or quetiapine (100-600 mg/day). A rapid titration schedule (5 days) until an optimal dose was reached was considered the rule unless severe side effects occurred. Based on the clinical efficacy and side effects during the follow-up period, the dose and type of antipsychotic medication could be changed by the treating physician. The mean equivalent chlorpromazine doses of antipsychotic medications [32] were $212.18 \mathrm{mg}$ (SD: 92.22) at baseline and $294.12 \mathrm{mg}$ (SD: 260.39) at the 3-year follow-up. The study protocol allowed for the use of anticholinergic agents, benzodiazepines and antidepressants for clinical reasons. Anticholinergic medication was never used prophylactically.

\subsection{Assessments}

\subsubsection{Premorbid and sociodemographic variables}

Premorbid and sociodemographic information was recorded from patients, relatives and medical records. The age at the time of onset of psychosis was defined as the age when the emergence of the first continuous (present most of the time) psychotic symptom occurred. The duration of untreated illness (DUI) was defined as the time from the first unspecific symptoms related to psychosis (for such a symptom to be considered, there should be no return to previous stable level of functioning) to initiation of adequate antipsychotic drug treatment; the duration of untreated psychosis (DUP) was defined as the time (months) from the first continuous (present most of the time) psychotic symptom to the initiation of adequate antipsychotic treatment (date when the first antipsychotic treatment in PAFIP was assigned and initiated). DUP was measured systematically to guarantee a valid and reliable measurement. Dating the onset of positive psychotic symptoms relied on information collected in a semi structured interview, based on the Symptom Onset in Schizophrenia (SOS) inventory [33] and SCID and was operationalized by estimating the date on the total SAPS score that would have met the threshold of $\geq 3$. Cross-referencing with milestones and memorable events was used to enhance the accuracy of dating. All of the interviews were conducted during the patient's first episode of psychosis. Family members and other carers also provided collateral reports for dating the onset of positive symptoms. Information gathered by a senior psychiatrist, nurses and social workers was considered to establish the DUP. After completion of all interviews, consensus-based best estimates were determined for variables in which there may have been discrepancies between clinician, patient, and family reports.

Other variables were gender; educational level (1. Primary education; 2.10 years of education or higher); living arrangements at the onset of psychosis (1. Living with relatives; 2 . Living alone and other status); occupational status for 2 years prior to the initial interview (1.Employment/student; 2.Unemployed) and premorbid adjustment scale (PAS) [34].

\subsubsection{Clinical variables}

Clinical symptoms of psychosis were assessed using the Scale for the Assessment of Negative Symptoms (SANS) [35], the Scale for the Assessment of Positive Symptoms (SAPS) [36] and their 
positive, disorganized and negative dimensions [37] and the 24item Brief Psychiatric Rating Scale (BPRS) [38].

Complete clinical evaluations were conducted at baseline, 6 weeks, 12 months and 36 months. The patients were followed in our outpatient clinic and were permitted rapid and easy access to a clinical appointment at any time, for any possible signs/symptoms of clinical exacerbation that might appear. A thorough clinical assessment was performed to evaluate the severity, duration and course of clinical symptomatology.

\subsubsection{Duration of psychosis after starting treatment (DAT)}

The SAPS scale was used to determine the duration of psychosis after treatment (DAT) at frequent intervals for 36 months after the initial presentation. Subscale scores were calculated prospectively for each week for hallucinations, delusions, bizarre behavior and positive formal thought disorder. DAT was estimated as the total number of weeks with a score of 3 or higher on any SAPS subscale during the 3-year follow-up. The DAT was recorded based on the severity of symptomatology during exacerbations and relapses throughout the follow-up period, completed with the medical records and discussed at consensus meetings involving two senior psychiatrists and a clinical nurse. All patients enrolled in PAFIP are regularly interviewed at PAFIP outpatient clinic at least during a 3year follow-up period; during this period, the frequency of clinical interviews varies based on patients' clinical status and to the discretion of PAFIP clinical team (from weekly to quarterly visits). In addition to these, protocol clinical interviews were regularly set up at baseline, 6 weeks, 3 months, 1 year, 2 years and 3 years. Relapse was defined among patients who achieved clinical improvement and stability (CGI rating $\leq 4$ and a decrease of at least $30 \%$ on BPRS total score and all BPRS key symptom items, by being rated $\leq 3$ for more than 4 consecutive weeks at some point during the first six months following program entry) and was defined as any of the following criteria occurring after clinical improvement: 1.- a rating of 5 or above on any key BPRS symptom items for at least 1 week; 2.- CGI rating of $\geq 6$ and a change score of CGI of "much worse" or "very much worse" for at least 1 week; 3.hospitalization for psychotic psychopathology; 4.- completed suicide. Exacerbation was defined as any 2-point increase of any of the key BPRS symptoms, excluding changes in which the rating remained at the nonpsychotic level $(i . e,<3$ ). The key BPRS symptoms were unusual thought content, hallucinations, suspiciousness, conceptual disorganization and bizarre behavior. Patients were considered to have relapsed if the relapse state lasted at least one week $[39,40]$.

The DAT was active psychotic symptoms during relapse/ exacerbation, defined as the number of weeks with a score of 3 or higher on any of the four SAPS items during the 3 years followup. After a patient was considered to have had a relapse/ exacerbation, weekly assessments (SAPS scores) were performed to determine prospectively the duration of active psychotic symptoms. However, an objective quantification of commence or severity of psychotic experienced by the patient is not easy to accurately attain. It can only be retrospectively assessed indirectly based on a patient's and family's overt communication of hallucinations, thought disorders or behavioral alterations and clinical history. Based on information gathered, the starting date of relapse was confirmed in a consensus meeting by the clinical team. The DAT was estimated as the total number of weeks with a score of 3 or higher on any SAPS items during the 3 years follow-up. This definition was based in previous criteria for DAT [27] and on the standardized positive remission criteria without the time criteria [41]. The active psychosis measurement after DUP was in the unit of weeks; however, as DUP had been measured in the unit of months, DAT was multiplied by a factor of 0,23 (divided by 52 weeks and multiplied by 12 months) to convert into months. This duration was added to the Duration of Untreated Psychosis (DUP) prior to presentation in order to create a new variable, Duration of Active Psychosis (DAP). To compare groups with higher and lower DUP, DAT and DAP, the data sets were divided into tertiles.

\subsubsection{Social functioning and functional recovery}

The Disability Assessment Scale (DAS) [42] was used to assess functional outcome at the 3-year follow-up by a psychiatrist and a social worker. At the end of the interview, an overall judgment of total functioning was established using the Global Evaluation (GE) (ranging from 0 , normal adjustment, to 5, severe maladjustment), with a consensus rating reached between the psychiatrist and the social worker. Good social functioning was defined as a score of 0 or 1 in the 3-year, whereas a score of 2 or more was considered poor social functioning.

Functional recovery was determined at the 3-year follow-up by collecting information independently from the patients and their relatives by a psychiatrist and a social worker. Information was gathered to determine whether the patient was in full- or parttime work or at school at the 3-year follow-up. The raters reached a consensus after evaluating a structured assessment of the academic or work performance. According to our previous study [43], we considered the patient to have achieved functional recovery when he/she was currently in part-time or full-time work or study with minimal disability (scores of 0 or 1 in the DAS).

\subsection{Statistical analysis}

Univariate analyses were conducted to explore the of functional outcome and recovery. The differences between patients with good or poor DAS and those between subjects who achieved recovery or did not were assessed using Student's $t$ test or the Mann-Whitney $U$ in the case of quantitative variables and chi-squared tests in the case of dichotomous or qualitative variables.

Two regression logistic models were performed to predict both functional outcome assessed by DAS and functional recovery including all of the significantly associated variables in the univariate analysis as predictors in a backward "Likelihood Ratio" test. DAP showed high collinearity with both DUP and DAT; therefore, two different models were performed, one including DAP and the other including DAT and DUP.

Finally, the receiver operating characteristic (ROC) curves were conducted to evaluate the area under the curve (AUC) for DAP, DAT and DUP and to assess the best cut-off values and their sensitivity, specificity and maximized Youden's index. An ROC curve provides a representation of diagnostic performance across the complete test's possible cut-offs. AUC, ranging from 0.5 to 1 , is a measure of the discriminative ability of the test. It has been shown that values of $\mathrm{AUC}=0.5$ indicate no discrimination, $A U C \geq 0.7$ indicates acceptable discrimination, AUC $\geq 0.8$ indicates excellent discrimination, and $A U C \geq 0.9$ indicates outstanding discrimination [44]. As a sensitivity analysis, the optimal DUP, DAT and DAP thresholds were obtained by maximizing Youden's index. This is a simple approach to minimizing error, equivalent to maximizing the sum of sensitivity and specificity (Youden's index = Sensitivity + Specificity-1). It ranges from 0 to 1 and can be interpreted as maximizing the true positive rate while minimizing the false positive rate [45].

The analyses were performed using the Statistical Package for Social Science, version 19.0 (SPSS Inc., Chicago, IL, USA). All of the statistical tests were two-tailed, and statistical significance was determined at the 0.05 level.

\section{Results}

Of 541 individuals referred to PAFIP from February 2001 to May 2011, 415 persons met the inclusion criteria and gave their 
written consent to participate in the study. A total of 307 subjects had sufficient information to assess functional recovery at three years. The patients who dropped out during the study or did not have sufficient available data to evaluate functional recovery at 3 years did not significantly differ from the final analyzed sample with respect to their initial sociodemographic and clinical characteristics, excepting in the academic level and the percentage of cannabis use (see Supplementary Table 5). DUP was comparable in the two groups. Interestingly, although the average DAT and DAP appear to be longer in the dropout subjects, they were more frequently classified in the tertiles of shorter DAT and DAP. The subjects included in the three clinical trials did not significantly differed in the good functional outcome or recovery rates.

The mean and median DUP were 13.62 months and 3 months, respectively; the cut-off points for 33.33th and 66.67th percentiles were 1 month and 8 months, respectively. The mean and median DAT were 4.88 and 2.66 , respectively; the cut-off points for 33.33 th and 66.67th percentiles were 1.53 months and 4.22 months, respectively. The mean and median DAP were 18.42 months and 8.80 months, respectively; the cut-off points for 33.33th and 66.67th percentiles were 4.55 months and 15.17 months, respectively.

\subsection{Demographic and clinical profile}

The baseline characteristics of the sample and comparisons between groups with good and poor functional recovery status and between groups with good and poor social functioning are depicted in Tables 1 and 2. Comparisons between the groups (according to 33.33th and 66.67th percentiles) of DUP, DAT and DUP are available in the supplementary Tables 1,2 and 3. A total of 180 patients had good social functioning $(58.63 \%$ of the included subjects and $43.37 \%$ of the total sample), and 124 achieved functional recovery ( $40.39 \%$ of the included subjects and $29.88 \%$ of the total sample) at the 3-year follow-up.

Table 1

Clinical variables by functional recovery at 3-years follow-up.

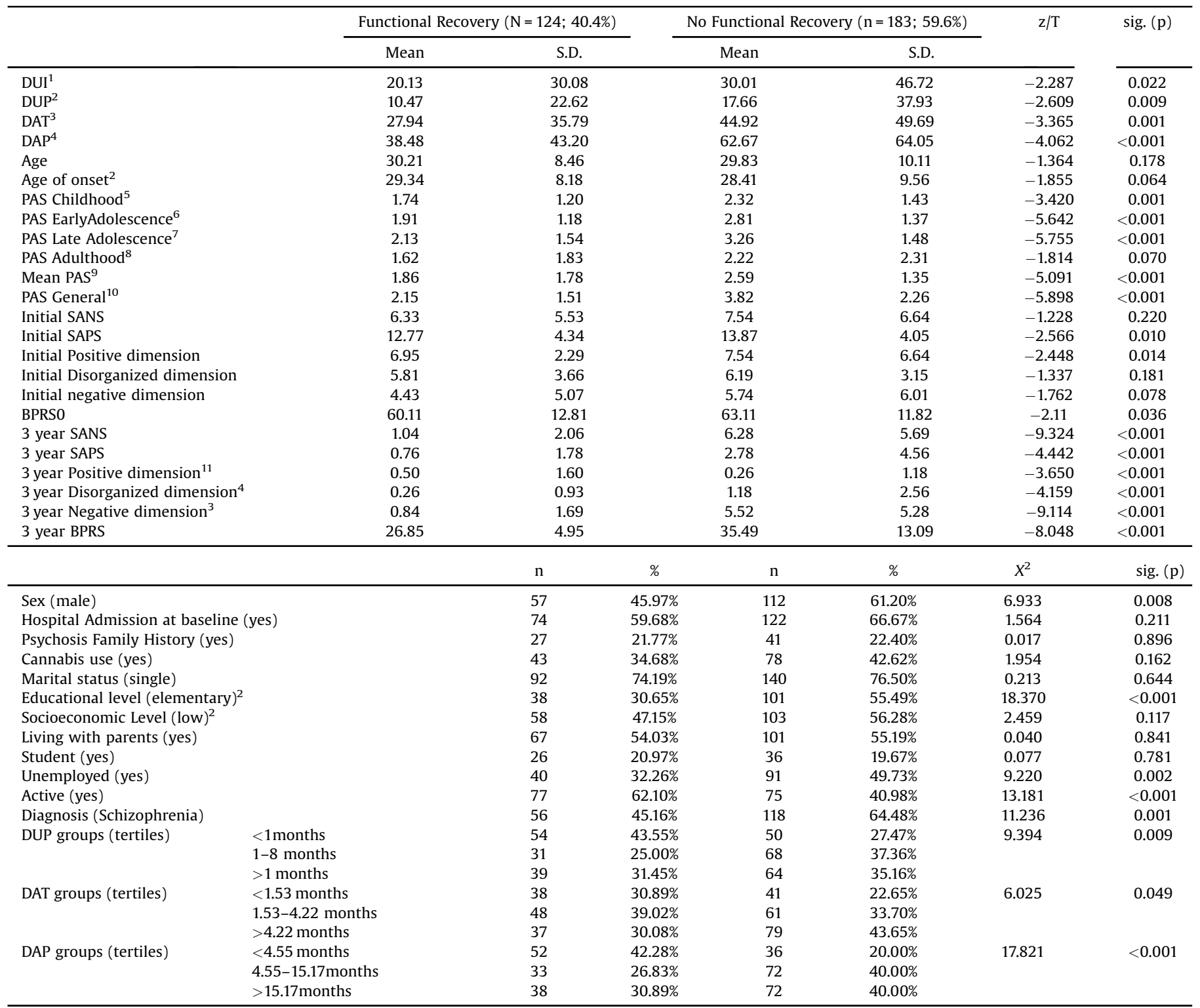

$1: n=299 ; 2: n=306 ; 3: n=304 ; 4: n=303 ; 5: n=282 ; 6: n=278 ; 7: n=218 ; 8: n=259: 9: n=273 ; 10: n=245 ; 11: n=302$. 
Table 2

Clinical variables by social functioning at 3-years follow-up.

\begin{tabular}{|c|c|c|c|c|c|c|c|}
\hline & \multicolumn{2}{|c|}{$\mathrm{DAS} \leqq 1(\mathrm{n}=180 ; 58.8 \%)$} & \multicolumn{3}{|c|}{ DAS $\geqq 2(n=126 ; 41.2 \%)$} & \multirow[t]{2}{*}{$\mathrm{z} / \mathrm{T}$} & \multirow[t]{2}{*}{ sig. (p) } \\
\hline & Mean & S.D. & Mean & & S.D. & & \\
\hline DUI $^{1}$ & 19.61 & 28.69 & 35.60 & & 52.74 & -3.386 & 0.001 \\
\hline DUP $^{2}$ & 10.53 & 21.13 & 20.89 & & 43.92 & -3.156 & 0.002 \\
\hline $\mathrm{DAT}^{3}$ & 3.92 & 5.30 & 7.62 & & 7.31 & -5.758 & $<0.001$ \\
\hline $\mathrm{DAP}^{4}$ & 14.50 & 21.94 & 28.70 & & 44.98 & -5.271 & $<0.001$ \\
\hline Age & 31.18 & 9.23 & 27.81 & & 9.03 & -3.745 & $<0.001$ \\
\hline Age of onset ${ }^{2}$ & 30.30 & 9.10 & 26.13 & & 7.76 & -4.413 & $<0.001$ \\
\hline PAS Childhood 5 & 1.84 & 1.20 & 2.45 & & 1.52 & -3.325 & 0.001 \\
\hline PAS EarlyAdolescence ${ }^{6}$ & 2.07 & 1.21 & 2.98 & & 1.39 & -5.541 & $<0.001$ \\
\hline PAS Late Adolescence ${ }^{7}$ & 2.29 & 1.53 & 3.51 & & 1.44 & -5.991 & $<0.001$ \\
\hline PAS Adulthood ${ }^{8}$ & 2.60 & 1.81 & 2.55 & & 2.45 & -3.015 & 0.003 \\
\hline Mean PAS ${ }^{9}$ & 1.94 & 1.82 & 2.80 & & 1.36 & -5.731 & $<0.001$ \\
\hline PAS General ${ }^{10}$ & 2.23 & 1.64 & 4.38 & & 2.14 & -7.749 & $<0.001$ \\
\hline Initial SANS & 6.09 & 5.43 & 8.47 & & 7.01 & -2.732 & 0.006 \\
\hline Initial SANS & 12.87 & 4.11 & 14.24 & & 4.21 & -3.118 & 0.002 \\
\hline Initial Positive dimension & 7.07 & 2.35 & 7.90 & & 2.41 & -2.860 & 0.004 \\
\hline Initial Disorganized dimension & 5.81 & 3.44 & 6.34 & & 3.25 & -1.688 & 0.091 \\
\hline Initial negative dimension & 4.18 & 4.91 & 6.74 & & 6.34 & -3.478 & 0.001 \\
\hline BPRSO & 60.11 & 12.41 & 64.60 & & 11.67 & -3.191 & 0.002 \\
\hline 3 year SANS & 1.27 & 2.41 & 8.25 & & 5.44 & -12.372 & $<0.001$ \\
\hline 3 year SAPS & 0.79 & 1.97 & 3.66 & & 5.02 & -6.757 & $<0.001$ \\
\hline 3 year Positive dimension ${ }^{3}$ & 0.47 & 1.14 & 2.14 & & 3.00 & -6.027 & $<0.001$ \\
\hline 3 year Disorganized dimension ${ }^{3}$ & 0.32 & 1.12 & 1.51 & & 2.87 & -5.524 & $<0.001$ \\
\hline 3 year Negative dimension ${ }^{3}$ & 1.03 & 2.13 & 7.30 & & 5.13 & -12.163 & $<0.001$ \\
\hline \multirow[t]{2}{*}{3 year BPRS } & 26.85 & 5.48 & 39.31 & & 13.48 & -11.178 & $<0.001$ \\
\hline & & $\mathrm{n}$ & $\%$ & $\mathrm{n}$ & $\%$ & $X^{2}$ & sig. (p) \\
\hline Sex (male) & & 81 & $45.00 \%$ & 89 & $70.63 \%$ & 19.726 & $<0.001$ \\
\hline Hospital Admission at baseline (yes) & & 106 & $58.89 \%$ & 89 & $70.63 \%$ & 4.424 & 0.035 \\
\hline Psychosis Family History (yes) & & 42 & $23.33 \%$ & 26 & $20.63 \%$ & 0.312 & 0.576 \\
\hline Cannabis use (yes) & & 66 & $36.67 \%$ & 56 & $44.44 \%$ & 1.870 & 0.171 \\
\hline Marital status (single) & & 127 & $70.56 \%$ & 106 & $84.13 \%$ & 7.515 & 0.006 \\
\hline Educational level (elementary) ${ }^{2}$ & & 62 & $34.64 \%$ & 76 & $60.32 \%$ & 19.685 & $<0.001$ \\
\hline Socioeconomic Level (low) ${ }^{2}$ & & 91 & $50.84 \%$ & 69 & $54.76 \%$ & 0.457 & 0.499 \\
\hline Living with parents (yes) & & 89 & $49.44 \%$ & 79 & $62.70 \%$ & 5.259 & 0.022 \\
\hline Student (yes) & & 34 & $18.89 \%$ & 29 & $23.02 \%$ & 0.772 & 0.380 \\
\hline Unemployed (yes) & & 59 & $32.78 \%$ & 71 & $56.35 \%$ & 16.853 & $<0.001$ \\
\hline Active (yes) & & 101 & $56.11 \%$ & 51 & $40.48 \%$ & 7.248 & 0.007 \\
\hline Diagnosis (Schizophrenia) & & 81 & $45.00 \%$ & 93 & $73.81 \%$ & 25.079 & $<0.001$ \\
\hline \multirow[t]{3}{*}{ DUP groups (tertiles) } & $<1$ months & 72 & $40.00 \%$ & 32 & $25.26 \%$ & 6.956 & 0.031 \\
\hline & $1-8$ months & 54 & $30.00 \%$ & 44 & $35.20 \%$ & & \\
\hline & $>1$ months & 54 & $30.00 \%$ & 49 & $39.20 \%$ & & \\
\hline \multirow[t]{3}{*}{ DAT groups (tertiles) } & $<1.53$ months & 57 & $31.84 \%$ & 21 & $16.94 \%$ & 24.853 & $<0.001$ \\
\hline & $1.53-4.22$ months & 74 & $41.34 \%$ & 35 & $28.23 \%$ & & \\
\hline & $>4.22$ months & 48 & $26.82 \%$ & 68 & $54.84 \%$ & & \\
\hline \multirow[t]{3}{*}{ DAP groups (tertiles) } & $<4.55$ months & 74 & $41.34 \%$ & 14 & $11.38 \%$ & 31.689 & $<0.001$ \\
\hline & 4.55-15.17months & 51 & $28.49 \%$ & 53 & $43.09 \%$ & & \\
\hline & $>15.17$ months & 54 & $30.17 \%$ & 56 & $45.53 \%$ & & \\
\hline
\end{tabular}

$1: n=298 ; 2: n=305 ; 3: n=303 ; 4: 302 ; 5: N=281 ; 6: n=277 ; 7: n=218 ; 8: n=258 ; 9: n=282 ; 10: n=244$.

\subsection{Predicting social functioning at 3 years}

Gender, educational level, employment status at baseline, diagnosis, age of onset, mean premorbid adjustment, positive and negative dimensions, baseline BPRS, hospital admission, DUP and DAT were included in the logistic regression model to predict social function status at the third year (Table 3 ). The final model $\left(\chi^{2}\right.$ : 77.939; Nagelkerke $R^{2}: 0.330 ; p<0.001$ ) included the following as predictors: age of onset, mean PAS score, initial BPRS score, gender, diagnosis and DAT. DAT was the main predictor in the logistic regression analysis (Wald: 13.974; $\mathrm{p}<0.001$ ).

The result of the second model that included DAP instead of DAT and DUP ( $\chi^{2}: 71.726$; Nagelkerke $\left.\mathrm{R}^{2}: 0.307 ; \mathrm{p}<0.001\right)$ had the following as final predictor variables (Supplementary Table 4): mean PAS score, initial BPRS score, age of onset, gender, educational level, diagnosis and DAP (Supplementary Table 4). Mean PAS was the main predictor in the logistic regression analysis (Wald: 8.668; $\mathrm{p}=0.003$ ).
The comparative ROC curves for DUP, DAT and DAP are shown in Fig. 1. The AUC was statistically significant for DUP $(A U C=0.604$; $\mathrm{p}=0.002)$, DAT (AUC $=0.693 ; \mathrm{p}<0.001)$ and DAP $(A U C=0.678$; $\mathrm{p}<0.001$ ). The optimal cut-off points were 0.85 months for DUP (sensitivity: 0.94; specificity: 0.27; Youden index: 0.203), 3.17 months for DAT (sensitivity: 0.68; specificity: 0.64; Youden index: 0.314 ) and 6.33 months for DAP (sensitivity: 0.84; specificity: 0.54; Youden index: 0.373). Relationships between sensitivity, specificity, Youden's Index and DAT thresholds are shown in Fig. 2.

\subsection{Predicting functional recovery at 3 years}

Gender, educational level, employment status at baseline, diagnosis, mean PAS, positive dimension and BPRS scores at baseline, DUP and DAT were included in the logistic regression model to predict functional recovery status at the third year. The final model $\left(\chi^{2}\right.$ : 41.663; Nagelkerke $\left.R^{2}: 0.188 ; p<0.001\right)$ included the following as predictors: mean PAS, educational level, working status at onset and DAT (Table 3 ). 
Table 3

Logistic regressions including DAT and DUP.

\begin{tabular}{|c|c|c|c|c|c|}
\hline \multicolumn{6}{|c|}{ Logistic Regression for Social Functioning (Das $>=2)^{1}$} \\
\hline \multirow[t]{2}{*}{ Predictor } & \multirow[t]{2}{*}{ Wald } & \multirow[t]{2}{*}{ Sig. } & \multirow[t]{2}{*}{$\operatorname{Exp}(B)$} & 95\% C.I. for $\operatorname{EXP}(B)$ & \\
\hline & & & & Lower & Upper \\
\hline DAT & 13.974 & $<0.001$ & 1.097 & 1.045 & 1.152 \\
\hline Mean PAS & 11.720 & 0.001 & 1.496 & 1.118 & 1.884 \\
\hline Initial BPRS & 8.154 & 0.004 & 1.033 & 1.010 & 1.057 \\
\hline Sex & 5.138 & 0.023 & 1.992 & 1.098 & 3.614 \\
\hline Age of Onset & 5.042 & 0.025 & 0.959 & 0.925 & 0.995 \\
\hline Diagnosis & 4.828 & 0.028 & 1.941 & 1.074 & 3.507 \\
\hline
\end{tabular}

Logistic Regressions for Non Functional Recovery ${ }^{2}$

\begin{tabular}{|c|c|c|c|c|c|}
\hline \multirow[t]{2}{*}{ Predictor } & \multirow[t]{2}{*}{ Wald } & \multirow[t]{2}{*}{ Sig. } & \multirow[t]{2}{*}{$\operatorname{Exp}(B)$} & \multirow{2}{*}{$\frac{95 \% \text { C.I. for } \operatorname{EXP}(B)}{\text { Lower }}$} & \multirow[b]{2}{*}{ Upper } \\
\hline & & & & & \\
\hline DAT & 4.850 & 0.028 & 1.054 & 1.006 & 1.105 \\
\hline Mean PAS & 10.081 & 0.001 & 1.449 & 1.152 & 1.821 \\
\hline Educational Level & 6.959 & 0.008 & 2.071 & 1.206 & 3.556 \\
\hline Working status at onset & 3.815 & 0.051 & 1.700 & 0.998 & 2.896 \\
\hline
\end{tabular}

${ }^{1}$ Model summary: $\mathrm{R}^{2}: 77.939 ; \mathrm{p}<0.001$; Nagelkerke R2: 0.330; Method: Backward LR; Initial variables: DUP, DAT, Age of onset, Mean PAS; Initial BPRS, Initial Positive, Disorganized and Negative Dimensions, Gender, Hospitalization, Educational Level, Marital Status, Unemployment.

${ }^{2}$ Model summary: $\mathrm{R}^{2}: 41.663 ; \mathrm{p}<0.001$; Nagelkerke $\mathrm{R}^{2}$ : 0.188; Method: Backward LR; Initial variables: DAT, DUP, Age of onset, Mean PAS; Initial BPRS, Initial Positive and Negative Dimensions, Gender, Hospitalization, Educational Level, Marital Status, Unemployment.

The result of the second model that included DAP instead of DAT and DUP $\left(\chi^{2}: 40.529\right.$; Nagelkerke $\left.R^{2}: 0.183 ; p<0.001\right)$ had the following as final predictor variables: mean PAS, initial positive dimension score, educational level and DAP (Supplementary Table 4).

The comparative ROC curves for DUP, DAT and DAP for predicting nonfunctional recovery at three years are shown in Fig. 1. The AUC was statistically significant for DUP $(A U C=0.585$; $\mathrm{p}=0.012$ ), DAT (AUC=0.612; $\mathrm{p}=0.001)$ and DAP $(\mathrm{AUC}=0.629$; $\mathrm{p}<0.001)$. The optimal cut-off points were 1.75 months for DUP (sensitivity: 0.70; specificity: 0.47; Youden index: 0.166), 2.99 months for DAT (sensitivity: 0.59; specificity: 0.61; Youden index: 0.196 ) and 6.92 months for DAP (sensitivity: 0.69; specificity: 0.56; Youden index: 0.255).

\section{Discussion}

The duration of active positive symptoms in the early phases of the illness has a significant impact on patients' functionality in the long term. Interestingly, in our study, the duration of active psychosis before antipsychotic treatment was initiated (DUP) did not show an independent significant association with functional outcome.

Active positive symptoms represent a dangerous mental state that might be "toxic" for the outcomes of patients with a first episode of psychosis. However, many previous studies have focused only on the effect of DUP on outcome; subsequently, longer DUP has been described as one of the most replicated predictors of worse clinical, functional and cognitive outcomes [12], whereas the active psychotic symptoms after treatment initiation has been poorly understood as a risk factor of worse outcome.

Interestingly, we initially found a relationship between a longer DUP and poorer social functioning or non-recovery (Tables 1 and 2 ), according to previous research [46], that did not remain significant in the multivariate analysis. This suggest that the association of DUP with functional outcomes is not independent but mediated by other predictors such as premorbid adjustment and other social factors. It has been previously suggested that DUP effects on functional outcomes during the first years of treatment may be mediated by social support and other social factors [47] and this may explain the inconclusive results in other neurotoxic effects such as cognition [48] or neuroimaging [19].

Only a limited number of studies have explored the impact of DAT or DAP on the evolution of the illness. Lyne et al. [27] reported that prolonged periods of DAP, but not DUP, were associated with negative symptoms at 18- and 24-month follow-up [27]. Barder et al. [26] evaluated DUP and DAT (defined as the period in weeks per year with a score of at least 4 in any of the items of the PANSS positive subscale) in patients with an FEP and divided them into three equally sized groups [26]. Only the subgroup with a longer DAT showed a significant intellectual decline during the 10-year follow-up. In accordance with these findings, we observed that longer DAT and DAP periods, but not DUP, were significantly associated with poorer social functioning at 3 years and with a lower likelihood of achieving functional recovery, that may be
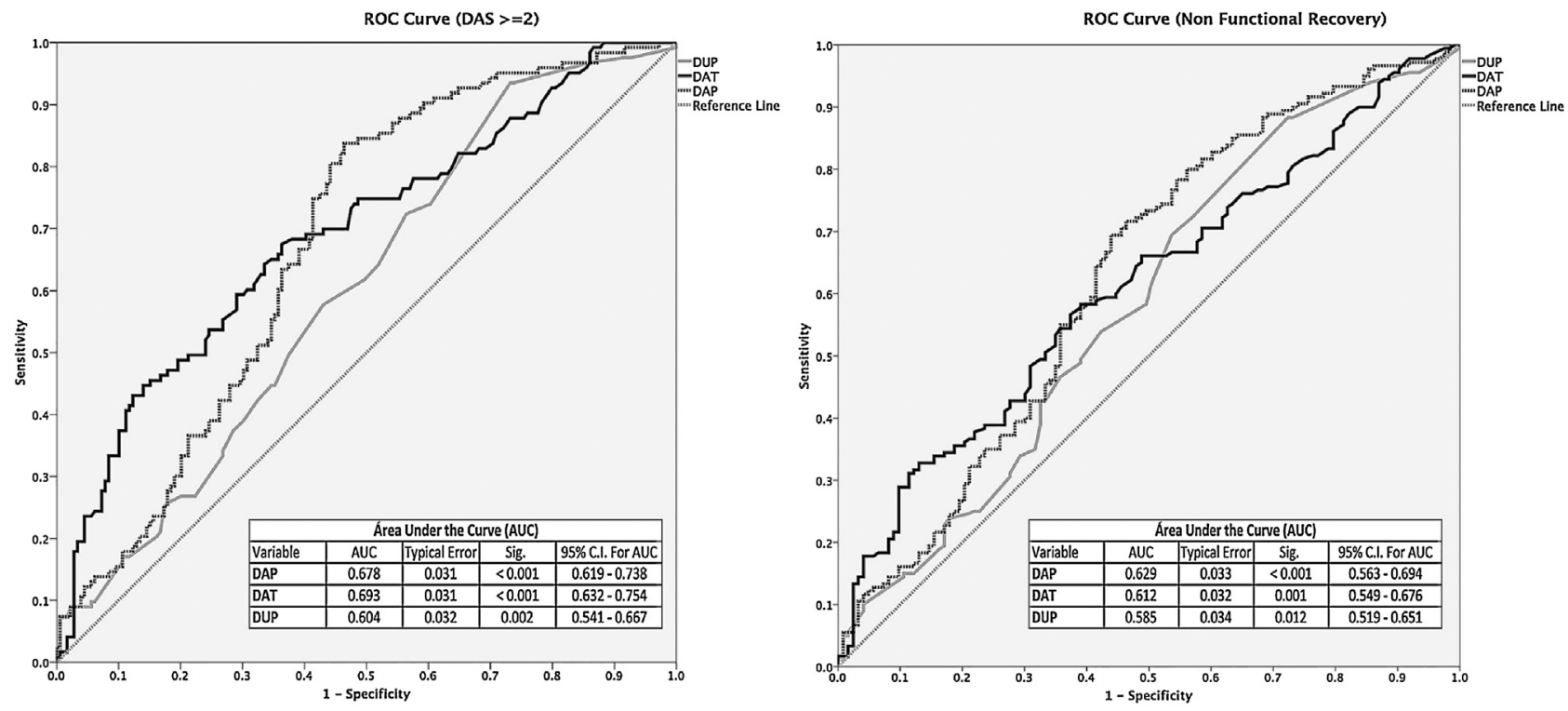

Fig. 1. ROC Curves for DUP, DAT and DAP. 


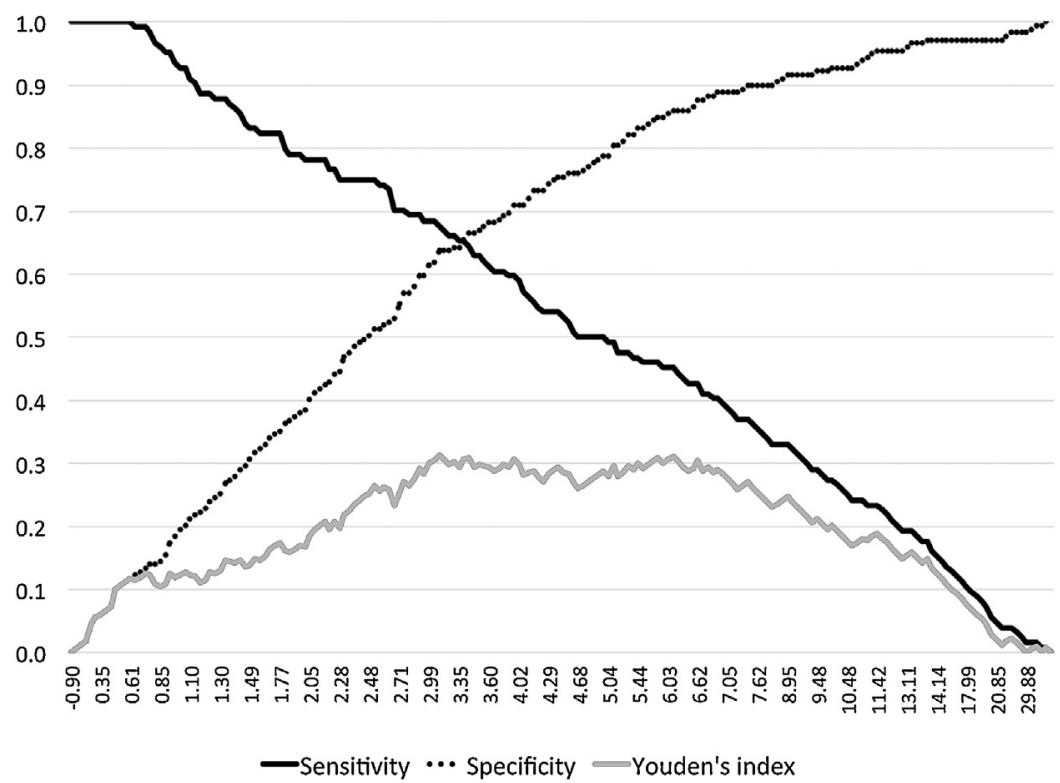

Fig. 2. Relationship between sensitivity, specificity and Youden's index (thresholds of DAT for the prediction of bad social functioning).

related to a poorer outcome on cognitive or negative symptomatology [46].

Whereas DAT was the main predictor for social functioning in the long term in our study, functional recovery was primarily predicted by premorbid adjustment and educational level. Given that the definition of recovery includes returning to work or academic activities, a number of variables that are not directly related to the illness process may limit the recovery rates, such as personal, social and economic factors [49].

When the ROC curves were analyzed, we only obtained a near acceptable value of 0.693 in the evaluation of thresholds of DAT for predicting social functioning. The optimal threshold of DAT, with a sensitivity of 0.68 and a specificity of 0.64 may help to discriminate the subjects with a poor social functional outcome and suggests that individuals with a total DAT less than 3.17 months may obtain greater benefit from symptomatic remission and relapse prevention. This cut-of suggests that even small periods of active psychotic symptoms may be associated to poorer social outcomes. The results regarding functional recovery do not allow for the establishment of an acceptable threshold for any of the periods. Premorbid adjustment and other predictor variables may moderate the relationship between active psychosis periods and recovery.

Our results suggest that the DAP period, as a modifiable variable, is the main focus of intervention to improve long-term functional results. Reducing the DAP period includes reducing the DUP, as previously stated, as well as the DAT period. Educational campaigns, improvements in health care networks and availability of assertive outreach teams seem to help reduce DUP periods [50]. As a period of active positive symptoms, DAT involves initial remission and also the number of relapses and the duration of symptomatic relapse. In this regard, DAT may be reduced by improving remission rates and time to remission and preventing relapses. Engaging patients in effective specialized treatments may help to increase adherence to treatment [40] and reduce time to remission [21] and specific interventions should be used to reduce substance that may worsen clinical outcome [51]. Since up to a quarter of patients with a first episode of psychosis may be treatment resistant [52], early detection and treatment of refractory psychosis should be a main focus of intervention to improve remission. Early use of clozapine in individuals with refractory psychosis may reduce DAT by reducing time to remission in selected patients [53]. Finally, improving adherence to medication as the best modifiable predictor of relapse in schizophrenia and first-episode psychosis patients may help to maintain symptomatic remission and reduce relapse rates [54].

Some limitations should be considered when interpreting our results. First, these results do not clarify the direction of causality between DAT and functional outcome. An alternative explanation is that a third variable associated with functional outcome is also associated with DAT. Second, the evaluation of the DAT period has been based on all possible information sources, including clinical records and prospective assessment. However, missing data and recall bias may be further limitations. Third, although the DAT definition is based on the persistence of positive symptoms, it is likely that other symptoms, such as negative symptoms, may have additional predictive value and toxicity effects. Finally, although our definitions of social functioning and functional recovery included standardized assessments and real-world outcomes, there is no consensus in these definitions, which may limit generalization of the results.

\section{Conclusions}

Diminishing the duration of active psychotic symptoms after the initiation of treatment is crucial to achieve long-term functional recovery. Specialized interventions aimed at improving remission rates and reducing relapses should result in shorter DAT periods and, subsequently, better functional outcomes. Mental health professionals may be fully aware of the modifiable factors that influence the functional recovery and design interventions to maximize clinical response and minimize the risk of relapse after clinical stabilization.

\section{Funding sources}

The study was carried out at the Hospital Marqués de Valdecilla, University of Cantabria, Santander, Spain, under the following grant supports: Plan Nacional de Drogas Research (2005-Orden sco/3246/2004); SENY Fundació (CI 2005-0308007); and Fundación Marqués de Valdecilla (API07/011); Gerencia Regional de Salud de Castilla y León (INT/M/04/17) 
Unrestricted educational and research grants from AstraZeneca, Pfizer, Bristol-Myers Squibb, and Johnson \& Johnson provided support for PAFIP activities. No pharmaceutical industry or institutional sponsors participated in the study design, data collection, analysis and interpretation of the results.

\section{Declaration of interest}

Dr. José María Pelayo-Terán has received lecture honoraria and travel support form Janssen Johnson \& Johnson, Lundbeck, Otsuka Pharmaceuticals, GlaxoSmithkline and EiLilly.

Prof. Benedicto Crespo-Facorro has received honoraria for consulting/advisory boards from Otsuka Pharmaceuticals and lecture honoraria from Janssen Johnson \& Johnson, Lundbeck, Roche and Otsuka Pharmaceuticals.

Prof. Rafael Tabarés-Seisdedos has received grants from or acted as a consultant for the following companies: AstraZeneca, Janssen, Eli- Lilly, Lundbeck, Novartis, Pfizer, Sanofi-Aventis, and Wyeth that were deposited into research accounts at the University of Valencia.

Dr. Rosa Ayesa-Arriola has received lecture honoraria and travel support form Lundbeck and Otsuka Pharmaceuticals.

Dr. Virginia Gajardo Galán, Dr. Marcos Gómez-Revuelta and Victor Ortiz-Garcia de la Foz report no additional financial support or other relationship relevant to the subject of this article.

\section{Acknowledgements}

This study was conducted as part of the clinical trial Comparative Study of Aripiprazole, Quetiapine and Ziprasidone in the Treatment of First-Episode Non-affective Psychosis (AZQ2005), ClinicalTrials.gov Identifier: NCT02305823.

The authors wish to thank the "Programa Asistencial de las Fases Iniciales de Psicosis" (PAFIP) research team and all patients and family members who participated in the study.

\section{Appendix A. Supplementary data}

Supplementary data associated with this article can be found, in the online version, at https://doi.org/10.1016/j.eurpsy.2018.03.003.

\section{References}

[1] Kraepelin E., Kraepelin E. Dementia praecox and paraphrenia. Huntington, N.Y: Krieger Publishing; 1971.

[2] AlAqeel B, Margolese HC. Remission in schizophrenia: critical and systematic review. Harv Rev Psychiatry 2012;20:281-97, doi:http://dx.doi.org/10.3109/ 10673229.2012.747804.

[3] Lally J, Ajnakina O, Stubbs B, Cullinane M, Murphy KC, Gaughran F, et al Remission and recovery from first-episode psychosis in adults: systematic review and meta-analysis of long-term outcome studies. Br J Psychiatry 2017;211:350-8, doi:http://dx.doi.org/10.1192/bjp.bp.117.201475.

[4] Wyatt RJ. Neuroleptics and the natural course of schizophrenia. Schizophr Bull 1991; 17:325-51.

[5] McGlashan T. Schizophrenia in translation: is active psychosis neurotoxic? Schizophr Bull 2006;32:609-13, doi:http://dx.doi.org/10.1093/schbul/sbl032.

[6] McGlashan $\mathrm{TH}$, Johannessen JO. Early detection and intervention with schizophrenia: rationale. Schizophr Bull 1996;22:201-22.

[7] Lieberman JA, Perkins D, Belger A, Chakos M, Jarskog F, Boteva K, et al. The early stages of schizophrenia: speculations on pathogenesis, pathophysiology, and therapeutic approaches. Biol Psychiatry 2001;50:884-97.

[8] Pelayo-Terán JM, Gajardo Galán VG, de la Ortiz-García de la Foz V, MartínezGarcía O, Tabarés-Seisdedos R, Crespo-Facorro B, et al. Rates and predictors of relapse in first-episode non-affective psychosis: a 3-year longitudinal study in a specialized intervention program (PAFIP). Eur Arch Psychiatry Clin Neurosci 2017;26:7, doi:http://dx.doi.org/10.1007/s00406-016-0740-3.

[9] Ayesa-Arriola R, Alcaraz EG, Hernández BV, Pérez-Iglesias R, López Moríñigo JD, Duta R, et al. Suicidal behaviour in first-episode non-affective psychosis: specific risk periods and stage-related factors. Eur Neuropsychopharmacol 2015;25:2278-88, doi:http://dx.doi.org/10.1016/j.euroneuro.2015.09.008.

[10] Perkins DO, Gu H, Boteva K, Lieberman JA. Relationship between duration of untreated psychosis and outcome in first-episode schizophrenia: a critical review and meta-analysis. Am J Psychiatry 2005;162:1785-804, doi:http://dx. doi.org/10.1176/appi.ajp.162.10.1785

[11] Marshall M, Lewis S, Lockwood A, Drake R, Jones P, Croudace T. Association between duration of untreated psychosis and outcome in cohorts of firstepisode patients: a systematic review. Arch Gen Psychiatry 2005;62:975-83, doi:http://dx.doi.org/10.1001/archpsyc.62.9.975.

[12] Penttilä M, Jääskeläinen E, Hirvonen N, Isohanni M, Miettunen J. Duration of untreated psychosis as predictor of long-term outcome in schizophrenia: systematic review and meta-analysis. Br J Psychiatry 2014;205:88-94, doi: http://dx.doi.org/10.1192/bjp.bp.113.127753.

[13] Murru A, Carpiniello B. Duration of untreated illness as a key to early intervention in schizophrenia: a review. Neurosci Lett 2016, doi:http://dx.doi. org/10.1016/j.neulet.2016.10.003 Epub ahead.

[14] Ito S, Nemoto T, Tsujino N, Ohmuro N, Mātsumoto K, Matsuoka H, et al Differential impacts of duration of untreated psychosis (DUP) on cognitive function in first-episode schizophrenia according to mode of onset. Eur Psychiatry 2015;30:995-1001, doi:http://dx.doi.org/10.1016/j. eurpsy.2015.08.004.

[15] Anderson KK, Voineskos A, Mulsant BH, George TP, McKenzie KJ. The role of untreated psychosis in neurodegeneration: a review of hypothesized mechanisms of neurotoxicity in first-episode psychosis. Can J Psychiatry 2014:59:513-7.

[16] Malla AK, Bodnar M, Joober R, Lepage M. Duration of untreated psychosis is associated with orbital-frontal grey matter volume reductions in first episode psychosis. Schizophr Res 2011;125:13-20, doi:http://dx.doi.org/10.1016/j. schres.2010.09.021.

[17] Crespo-Facorro B, Roiz-Santiáñez R, Pelayo-Terán JM, Rodríguez-Sánchez JM, Pérez-Iglesias R, González-Blanch C, et al. Reduced thalamic volume in firstepisode non-affective psychosis: correlations with clinical variables, symptomatology and cognitive functioning. Neuroimage 2007;35:1613-23, doi:http://dx.doi.org/10.1016/j.neuroimage.2007.01.048.

[18] Rund BR, Barder HE, Evensen J, Haahr U, ten Velden Hegelstad W, Joa I, et al. Neurocognition and duration of psychosis: a 10-year follow-up of first-episode patients. Schizophr Bull 2016;42:87-95, doi:http://dx.doi.org/10.1093/schbul/ sbv083.

[19] Anderson KK, Rodrigues M, Mann K, Voineskos A, Mulsant BH, George TP, et al. Minimal evidence that untreated psychosis damages brain structures: a systematic review. Schizophr Res 2015;162:222-33, doi:http://dx.doi.org/ 10.1016/j.schres.2015.01.021.

[20] Rund BR. Does active psychosis cause neurobiological pathology? A critical review of the neurotoxicity hypothesis. Psychol Med 2014;44:1577-90, doi: http://dx.doi.org/10.1017/S0033291713002341.

[21] Jordan G, Veru F, Lepage M, Joober R, Malla A, lyer SN. Pathways to functional outcomes following a first episode of psychosis: the roles of premorbid adjustment, verbal memory and symptom remission. Aust New Zeal J Psychiatry 2017, doi:http://dx.doi.org/10.1177/0004867417747401 486741774740.

[22] Simonsen C, Faerden A, Romm KL, Berg AO, Bjella T, Sundet K, et al. Early clinical recovery in first-episode psychosis: symptomatic remission and its correlates at 1-year follow-up. Psychiatry Res 2017;254:118-25, doi:http://dx. doi.org/10.1016/j.psychres.2017.04.050.

[23] Friis S, Melle I, Johannessen JO, Røssberg JI, Barder HE, Evensen JH, et al. Early predictors of ten-year course in first-episode psychosis. Psychiatr Serv 2016;67:438-43, doi:http://dx.doi.org/10.1176/appi.ps.201400558.

[24] Wiersma D, Nienhuis FJ, Slooff CJ, Giel R. Natural course of schizophrenic disorders: a 15-year followup of a Dutch incidence cohort. Schizophr Bull 1998:24:75-85.

[25] Emsley R, Chiliza B, Asmal L, Harvey BH. The nature of relapse in schizophrenia. BMC Psychiatry 2013;13:50, doi:http://dx.doi.org/10.1186/1471-244X-13-50.

[26] Barder HE, Sundet K, Rund BR, Evensen J, Haahr U, ten Velden Hegelstad W, et al. 10 year course of IQ in first-episode psychosis: relationship between duration of psychosis and long-term intellectual trajectories. Psychiatry Res 2015;225:515-21, doi:http://dx.doi.org/10.1016/j.psychres.2014.11.054.

[27] Lyne J, Joober R, Schmitz N, Lepage M, Malla A. Duration of active psychosis and first-episode psychosis negative symptoms. Early Interv Psychiatry 2017; 11:63-71, doi:http://dx.doi.org/10.1111/eip.12217.

[28] Pelayo-Terán JMJM, Pérez-Iglesias R, Ramírez-Bonilla MML, González-Blanch C, Martínez-García O, Pardo-García G, et al. Epidemiological factors associated with treated incidence of first-episode non-affective psychosis in Cantabria: insights from the clinical programme on early phases of psychosis. Early Interv Psychiatry 2008;2:178-87, doi:http://dx.doi.org/10.1111/j.17517893.2008.00074.x.

[29] First MB, Spitzer RL, Gibbon M, Williams JBW. Structured clinical interview for DSM-IV Axis I disorders (Clinician Version). New York: New York State Psychiatric Institute Biometrics Department; 2001.

[30] Crespo-Facorro B, Pérez-Iglesias R, Ramirez-Bonilla M, Martínez-García O, Llorca J, Luis Vázquez-Barquero J, et al. A practical clinical trial comparing haloperidol, risperidone, and olanzapine for the acute treatment of firstepisode nonaffective psychosis. J Clin Psychiatry 2006;67:1511-21, doi:http:// dx.doi.org/10.4088/JCP.v67n1004.

[31] Crespo-Facorro B, Pérez-Iglesias R, Mata I, Mata I, Ortiz-Garcia de la Foz V, Valdizan EM, et al. Aripiprazole, ziprasidone, and quetiapine in the treatment of first-episode nonaffective psychosis: results of a 6-week, randomized, flexible-dose, open-label comparison. J Clin Psychopharmacol 2013;33:21520, doi:http://dx.doi.org/10.1097/JCP.0b013e3182825c1e. 
[32] Gardner DM, Murphy AL, O’Donnell H, Centorrino F, Baldessarini RJ International consensus study of antipsychotic dosing. Am J Psychiatry 2010;167:686-93, doi:http://dx.doi.org/10.1176/appi.ajp.2009.09060802.

[33] Perkins DO, Leserman J, Jarskog LF, Graham K, Kazmer J, Lieberman JA. Characterizing and dating the onset of symptoms in psychotic illness: the Symptom Onset in Schizophrenia (SOS) inventory. Schizophr Res 2000;44:110.

[34] van Mastrigt S, Addington J. Assessment of premorbid function in first-episode schizophrenia: modifications to the Premorbid Adjustment Scale. J Psychiatry Neurosci 2002;27:92-101.

[35] Andreasen NC. Scale for the sssessment of negative symptoms (SANS). Iowa: University of Iowa; 1983.

[36] Andreasen NC. Scale for the assessment of positive symptoms (SAPS). Iowa City: University of Iowa; 1984.

[37] Grube BS, Bilder RM, Goldman RS. Meta-analysis of symptom factors in schizophrenia. Schizophr Res 1998;31:113-20.

[38] Overall JE, Gorham DR. The brief psychiatric rating scale. Psychol Rep 1962;10:799-812, doi:http://dx.doi.org/10.2466/pr0.1962.10.3.799.

[39] Caseiro O, Pérez-Iglesias R, Mata I, Martínez-Garcia O, Pelayo-Terán JMJM, Tabares-Seisdedos R, et al. Predicting relapse after a first episode of nonaffective psychosis: a three-year follow-up study. J Psychiatr Res 2012;46:1099-105, doi:http://dx.doi.org/10.1016/j.jpsychires.2012.05.001.

[40] Mayoral-van Son J, de la Foz VO-G, Martinez-Garcia O, Moreno T, ParrillaEscobar M, Valdizan EM, et al. Clinical outcome after antipsychotic treatment discontinuation in functionally recovered first-episode nonaffective psychosis individuals: a 3-year naturalistic follow-up study. J Clin Psychiatry 2016;77:492-500, doi:http://dx.doi.org/10.4088/JCP.14m09540.

41] Andreasen NC, Carpenter WT, Kane JM, Lasser RA, Marder SR, Weinberger DR Remission in schizophrenia: proposed criteria and rationale for consensus. Am J Psychiatry 2005;162:441-9, doi:http://dx.doi.org/10.1176/appi.ajp.162.3.441.

[42] World Health Organization. WHO psychiatric disability assessment schedule (WHO/DAS), with a guide to its use. Geneva: WHO Publications Center; 1988.

[43] González-Blanch C, Perez-Iglesias R, Pardo-García G, Rodríguez-Sánchez JM, Martínez-García O, Vázquez-Barquero JL, et al. Prognostic value of cognitive functioning for global functional recovery in first-episode schizophrenia. Psychol Med 2010;40:935-44, doi:http://dx.doi.org/10.1017/ S0033291709991267.
[44] Hajian-Tilaki K. Receiver operating characteristic (ROC) curve analysis for medical diagnostic test evaluation. Casp J Intern Med 2013;4:627-35.

[45] Youden WJ. Index for rating diagnostic tests. Cancer 1950;3:32-5.

[46] Santesteban-Echarri O, Paino M, Rice S, González-Blanch C, McGorry P, Gleeson J, et al. Predictors of functional recovery in first-episode psychosis: a systematic review and meta-analysis of longitudinal studies. Clin Psychol Rev 2017:58:59-575, doi:http://dx.doi.org/10.1016/j.cpr.2017.09.007.

[47] Norman RMG. Are the effects of duration of untreated psychosis socially mediated? Can J Psychiatry 2014;59:518-22, doi:http://dx.doi.org/10.1177/ 070674371405901004

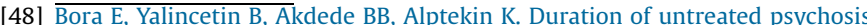
and neurocognition in first-episode psychosis: a meta-analysis. Schizophr Res 2017, doi:http://dx.doi.org/10.1016/j.schres.2017.06.021.

[49] Jääskeläinen E, Juola P, Hirvonen N, McGrath JJ, Saha S, Isohanni M, et al. A systematic review and meta-analysis of recovery in schizophrenia. Schizophr Bull 2013;39:1296-306, doi:http://dx.doi.org/10.1093/schbul/sbs130.

[50] Larsen TK, Joa I, Langeveld J, Johannessen JO. Optimizing health-care systems to promote early detection of psychosis. Early Interv Psychiatry 2009;3:S13, doi:http://dx.doi.org/10.1111/j.1751-7893.2009.00125.x.

[51] Oluwoye O, Monroe-DeVita M, Burduli E, Chwastiak L, McPherson S, McClellan $\mathrm{JM}$, et al. Impact of tobacco, alcohol and cannabis use on treatment outcomes among patients experiencing first episode psychosis: data from the national RAISE-ETP study. Early Interv Psychiatry 2018, doi:http://dx.doi.org/10.1111/ eip.12542.

[52] Lally J, Ajnakina O, Di Forti M, Trotta A, Demjaha A, Kolliakou A, et al. Two distinct patterns of treatment resistance: clinical predictors of treatment resistance in first-episode schizophrenia spectrum psychoses. Psychol Med 2016;46:3231-40, doi:http://dx.doi.org/10.1017/S0033291716002014.

[53] Agid O, Remington G, Kapur S, Arenovich T, Zipursky RB. Early use of clozapine for poorly responding first-episode psychosis. J Clin Psychopharmacol 2007;27:369-73, doi:http://dx.doi.org/10.1097/jcp.0b013e3180d0a6d4.

[54] Alvarez-Jimenez M, Priede A, Hetrick SEE, Bendall S, Killackey E, Parker AGG, et al. Risk factors for relapse following treatment for first episode psychosis: a systematic review and meta-analysis of longitudinal studies. Schizophr Res 2012;139:116-28, doi:http://dx.doi.org/10.1016/j.schres.2012.05.007. 